\title{
Age wise distribution of colorectal cancer: An institutional observational study
}

\author{
Pramila Kumari ${ }^{1}$, Neeti Sharma ${ }^{2}$, Praveen Kumar Khatri ${ }^{1}$, Satya Narayan ${ }^{1}$ \\ Saroj Kumari ${ }^{1}$, Kamlesh Kumar Harsh ${ }^{3}$, Shankar Lal Jakhar ${ }^{3}$, HS Kumar ${ }^{4}$ \\ Medical officer ${ }^{1}$, Associate professor ${ }^{2}$, Assistant professor ${ }^{3}$, Head of Department and senior professor ${ }^{4}$ \\ Department of Radiation Oncology, SP Medical College and Associated group of Hospital, Bikaner, \\ Rajasthan, India
}

\begin{abstract}
:
Background: Overall, the incidence of colorectal cancer appears to be stable or diminishing. However, based on our regional cancer institute's datas, we have observed the increasing incidence of colorectal cancer in patients $\leq 40$ age. The aim of this study was to verify the rising trend, clinico-pathological features and survival in colorectal cancer in patients $\leq 40$, in comparison to patients $>40$ age.

Materials and methods: A retrospective study was conducted to review all patients $\leq 40$ age and more than 40 year of age separatly with a diagnosis of colorectal cancer from January 2004 to December 2012.

Results: Young patients were $24.17 \%$ of total 1096 colorectal cases. In young patients $60.37 \%$ were male and $39.63 \%$ were female. $9 \%$ young had family history \& only $8 \%$ had history of alcohol intake. Onset of symptoms to reaching diagnosis period is longer in younger patients.(Range 3 months to 1 year in young, while 1 months to 6 months in older). Higher pathological T stage was seen in the younger age group when compared with patients above 40 years. Also the younger age group showed more advanced $N$ stage when compared with patients above 40 years. With final TNM staging, in younger age group 66\% were in stage IV and $30 \%$ were in stage III. Eighty percent of all young cancer deaths were within 22 months (from 8months to 22 months).

Conclusion: Above results show the aggressive nature and late diagnosis of carcinoma colorectal in young. These data highlight a need for thorough evaluation of young with colorectal symptoms and in high risk population, also life style modification agenda by Govt .or non Govt. organization.
\end{abstract}

\section{Introduction}

Worldwide colorectal carcinoma cases are increasing and now days it ranks third in most commonly occurring cancers.[1] Incidence of colorectal cancer is higher in affluent and western countries and most of the variation is due to changing pattern in the way of living and environmental factors, which can be prevented. [2] Colorectal cancers in young are mostly of poor histology, signet ring features, and mucinous present at advanced stages.[3] Kindred and twin studies estimated that in all CRC cases approximately 10-30\% are in familial form of the disease .In all familial cases approximately 5\% of cases are associated with highly penetrant inherited mutations, the etiologies of the remaining familial CRCs are not completely known. [4] The factors responsible for development of sporadic (60-85\%) colorectal cancers are, age beyond 50 years; consumption of highly saturated fat, over cocked and red meat; ionizing radiation exposure, particularly to pelvic part; and diet deficient in calcium; environmental and industrial pollution.[5,6,7] Some agricultural and health studies in United States has proved that elevated risk of CRC also correlated with exposure to pesticides.[8]

Many affluent Asian countries having similar CRC incidence to that in the West. [9] National healthcare systems and health insurance cover only a minority of people in most Asian countries. So, healthcare facilities are very limited in many communities of low socio-economic status and rural area. [10] There are substantial evidence of lifestyle factors, (smoking, drinking, low physical activity, diet) causing alterations to DNA, such as DNA methylation, histone modification, expression of micro RNAs and changes of the chromatin structure. [11,12]

Incidence of colorectal carcinoma is higher in the United States, Australia, New Zealand, and lowest in Africa and some parts of Asia.[13] However, these incidence rates may be affected by some types of biases, as for example in developing countries underreporting is seen at very high level .A previous analytical study conducted between 1984-2005 in people<40 years of age showed that incidence of CRC increased $3.8 \%$ per year. [14]

At our center, we have observed an increased incidence of colorectal cancers in younger age group in recent years. So our study was designed to report demographic, clinical and histopathological features differences between patients younger than 40 years and older colorectal carcinomas (CRC) cases. This is based 
on hospital based cancer registries. The main purpose of our study is early diagnosis and management for younger population who have alarming signs and having family history related to CRCs.

\section{Materials and Methods}

The observational study was conducted in the Oncology department of regional cancer center. All CRC patients' data reviewed retrospectively from January 2004 to December 2012. The patients were then grouped according to age.Charts were made and analyzed with respect to patient's age ,gender, site of primary tumor, presenting symptom and their duration, tumor staging, and survival by reviewing previous medical records ,histopathology reports and discharge summaries.

Colorectal cancers were typed into three main groups: proximal colon, distal colon and rectum.TNM staging(AJCC)system was used for staging. Young patients were studied separately. Clinical and pathological dataof young patients were compared with older patients. Both urban and rural populations were included. Follow up was recorded by direct meeting with patients in out patient's clinic or telephonically .In out patient's clinic if patient is visiting, examinations include, history by patient, digital rectal examination, CEA level every three months. Ultrasound and CECT abdomen and radiograph of chest yearly. Colonoscopy was advised annually for the first two years and then once in three years if last finding was uneventful.

Since we did not have any previous data of cancer patients in this area, our data were compared on the same aspect as that of colorectal cancers registered in population-based cancer registries (PBCR) from Bangalore, Chennai, Delhi, Mumbai, and Kolkata in 2006-2008 to estimate any deviation in any parameter if at all.

III.

Results

A total of 1096 CRC cases were analyzed for our study

Demographic:

Age range was 9-90 years, and median age at diagnosis was 42 year. The distribution of colorectal cancer with age range is shown in [Table - 1]. A total of $265(24.17 \%)$ patients of age 40 years or younger were diagnosed. Three cases were diagnosed in the paediatric (defined as <20 years) age group.

Table 1

\begin{tabular}{|lll|}
\hline Age (years) & No. & \% \\
\hline$<10$ & 1 & .09 \\
\hline $10-20$ & 2 & 1.82 \\
\hline $21-30$ & 88 & 8.02 \\
\hline $31-40$ & 158 & 14.41 \\
\hline $41-50$ & 296 & 27 \\
\hline $51-60$ & 262 & 23.9 \\
\hline $61-70$ & 198 & 18.06 \\
\hline $71-80$ & 57 & 5.2 \\
\hline$>80$ & 14 & 1.28 \\
\hline
\end{tabular}

Location of primary tumor: Of all CRC cases 654 (59.67\%) were rectal , and rectal predominance was seen in both age groups. Rectal cases were $(58.72 \%)$ in $>40$ years and in $<40$ years ,were $(62.64 \%)$.

Gender: Total of 1096 cases, 687 (62.7\%) were males and 409 (37.3\%) were females. Male predominance was seen in both above $(63.4 \%)$ and below 40 years $(61.5 \%)$. (Shown inTable-2)

Histopathology: Histology reports of most of the CRC showed adenocarcinoma. Also those above 40 years, majority were having moderately-differentiated adenocarcinoma. However, among those below 40 years of age, majority had poorly differentiated mucin-secreting adenocarcinoma. (Shown in table- 2)

Higher pathological T stage was seen in the younger age group when compared with patients above 40 years. Also the younger age group showed more advanced $\mathrm{N}$ stage when compared with patients above 40 years. With final TNM staging, in younger age group $66 \%$ were in stage IV and $30 \%$ were in stage III. [15] Table-2

Onset of symptom to diagnosis period: Onset of symptoms to reaching diagnosis period is longer in younger patients. (Range 3 months to 1 year in young, while 1 months to 6 months in older. Table [2]

Table2: Comparison of demographic features, histopathology, Tumor size and Nodal state findings in the two age groups.

\begin{tabular}{|lcll|}
\hline & & & \\
\hline & \multicolumn{1}{c|}{ Total } & >40 years & $<$ y0 years \\
\hline No. & $1096(100 \%)$ & $831(75.82)$ & $265(24.17)$ \\
\hline Sex & & & $160(60.37)$ \\
\hline Male & $687(62.68 \%)$ & $527(63.41 \%)$ & \\
\hline
\end{tabular}

DOI: $10.9790 / 0853-1601040105$

Www.iosrjournals.org 
Age wise distribution of colorectal cancer: An institutional observational study

\begin{tabular}{|lccc|}
\hline Female & $409(37.31)$ & $304(36.58 \%)$ & $105(39.62)$ \\
\hline Site & & & $166(62.64)$ \\
\hline Rectum & $654(59.67)$ & $488(58.72)$ & $99(37.35)$ \\
\hline Colon & $442(40.32)$ & $343(41.27)$ & $20(7.54)$ \\
\hline Grading of HPE & & $320(38.50)$ & $43(16.22)$ \\
\hline Well differentiated & $340(31.02)$ & $343(41.27)$ & $202(76.22)$ \\
\hline Moderately differentiated & $386(35.21)$ & $168(20.21)$ & $36(14.34)$ \\
\hline Poorly differentiated & $370(33.75)$ & & $105(48.67)$ \\
\hline T-Stage & & $319(38.38)$ & $124(46.47)$ \\
\hline T1-2 & $355(32.39)$ & $313(37.66)$ & $11(4.15)$ \\
\hline T3 & $418(38.13)$ & $199(23.94)$ & $146(55.09)$ \\
\hline T4 & $323(29.47)$ & & $108(40.75)$ \\
\hline N-Stage & & $264(31.76)$ & $58(21.88)$ \\
\hline N0 & $275(25.09)$ & $330(39.71)$ & $145(54.71)$ \\
\hline NI & $476(43.43)$ & $237(28.52)$ & $62(23.39)$ \\
\hline N2 & $345(31.47)$ & & \\
\hline Onset of symptom to diagnosis period & $502(60.40)$ & $268(32.25)$ \\
\hline$<6$ month & $61(7.34)$ & \\
\hline 6months-1year & & \\
\hline$>1$ year & & & \\
\hline & & & \\
\hline
\end{tabular}

Survival: Among young patients $80 \%$ expired within twenty two months after diagnosis. [16]

\section{Discussion}

In general, colorectal cancer is a disease of elderly, majority of patients diagnosed after the age of 55 years .[17]The incidence of CRCs is higher in the western countries as compared to India, and it is the tenth leading cancer in India [18]. Now- a -days in Asia CRCs cases has been reported to occur with a greater frequency in younger patients (usually $<40$ years old), although the United States also has shown an increase incidence of colorectal cancer in the young.[19] Genetic and familial etiologies account for less than $20 \%$ of colorectal cancers in the US and the remaining $80 \%$ of cases are due to multiple risk factors, in which most common is the dietary factor.[20]

The median age for CRCs was 71 year ,in SEER statistics 2008. [21] The median age in our series was 43 year, this age figure is much younger than in published studies.[22] [23]The youngest patient in our series was a 9-year-old male child. Two hundred and sixty five cases $(24.17 \%)$ presented $\leq 40$ years age. This was comparable with those reported by Nath et al., [24] Pal et al., [25] and Gupta et al. [26] but was higher than those in the PBCR [27] from Bangalore, Chennai, Mumbai, in 2006-2008 and slightly lower than PBCR of Delhi and Kolkata. Family history was present in $24[9 \%]$ patients and history of heavy alcohol intake was in $21[8 \%]$ patients. In this series, the male to female ratio was $1.52: 1$ which was in accordance with male preponderance reported in the literature.[28] [29]

Table3: Comparison of number of patients(n),percentage of patients(\%), mean age $\pm \mathrm{SD}$,stratified by 10 years age groups between ATRCTRI a HBCR,(2004-2012) and PBCR of Banglore ,Mumbai, Delhi, Chennai , Kolkatta .(2006-2008)

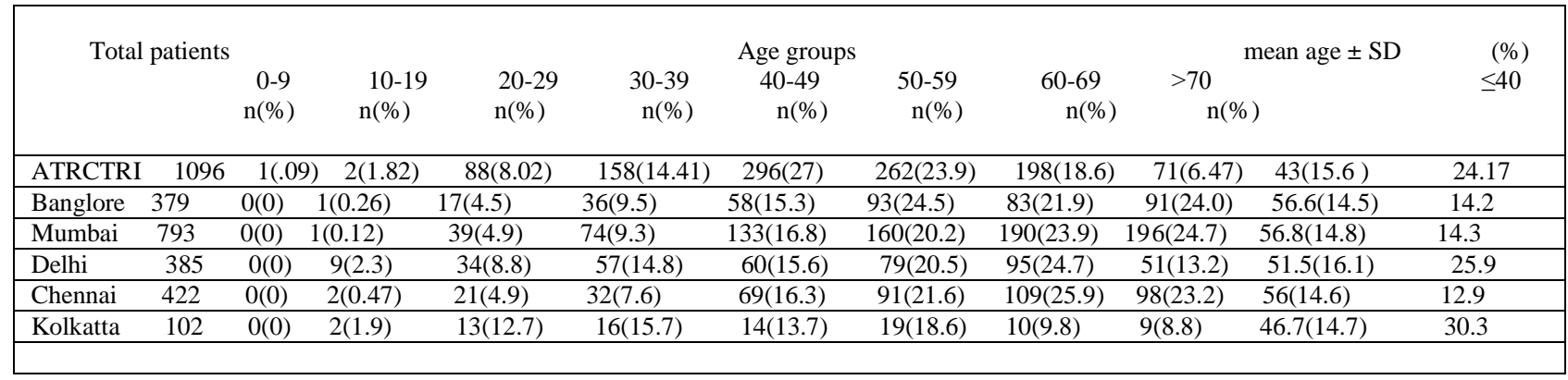

ATRCTRI-Acharya tulsi, regional cancer hospital and research institute Bikaner, HBCR-Hospital based cancer registries, PBCR- Population based cancer registries, SD-Standard deviation, n-Number of patients.

Because poor prognosis is affixed to colorectal cancer affecting young population $\leq 40$ years age, so this is the main concern of our study. Dukes and Bussey both described lymphatic metastasis in patients below 40 at higher rate. Recio and Bussey reported that more than half of the tumors in young patients were of high grade; in comparison, only one fifth of tumors were of high grade in the older CRCs cases.[30]In our study 
among $\leq 40$ years, majority i.e., $76.22 \%$ cases were poorly differentiated and mucin-secreting adenocarcinoma and $86.41 \%$ cases presented at advanced pathologic stage (T3 and T4).The reason for this is not clear. Substantial number of gene variants and or modifications of gene expression have been explored in recent years to identify young-onset CRC-specific genomic sequences.[31],[32]

\section{Conclusion}

The above data highlights, that a high index of suspicion among young adults is necessary ,i.e (a) thorough evaluation of young patients with colorectal symptoms, (b) life style modification agenda and cancer awareness program by Govt or Non Govt. organization periodically,(c) Early screening in high-risk individuals All may improve young-onset CRC prognosis.

Hence, further studies and research are required to find out whether finding suggest regional factors or it is indicative of a changing pattern of occurrence in colorectal cancers. If the second reason prevails, it is to be found out whether it is due to genetic factors or factors related to environmental changes, including changing food habits, and should be evaluated with more institutional studies. Although exact incidence rate cannot be provided by a hospital-based study, the information would be useful in showing that young-onset CRCs cases exhibit more aggressive pathologic characteristics, delay in diagnosis and advanced stage at presentation.

\section{References}

[1]. International Agency for Research on Cancer, Lyon (France) 2013. Available from WWW: http://globocan.iarc.fr0 years: an analysis of the surveillance, epidemiology, and end results database. Cancer. 2010;116: 4354-4359. Johnson I T, Lund E K. Review article: nutrition, obesity and colorectal cancer. Aliment Pharmacol Ther. 2007;26(2):161-181.

[2]. Johnson I T, Lund E K. Review article: nutrition, obesity and colorectal cancer. Aliment Pharmacol Ther. 2007;26(2):161-181.

[3]. You YN, Xing Y, Feig BW, et al. Young-onset colorectal cancer: is it time to pay attention? Arch Intern Med. 2012;172(3): 287289.

[4]. Richardson LC, Rim SH. Vital signs: colorectal cancer screening among adults aged 50-75 years United States, 2008. MMWR Morb Mortal Wkly Rep. 2010;59(26):808-812.

[5]. Berg JS. Proceedings of the 2nd National Conference on Cancer of the Colon and Rectum. American Cancer Society: Bal Harbor, FL; 1973.5

[6]. Zaridze DG. Environmental etiology of large-bowel cancer. J Natl Cancer Inst 1983;70:389-400. 6

[7]. Sandler RS, Sandler DP. Radiation induced cancers of the colon and rectum. Gastroenterology 1983;84:51-7.

[8]. Lee WJ, Sandler DP, Blair A, et al. Pesticide use and colorectal cancer risk in the Agricultural Health Study. Int J Cancer. 2007;121:339-346.

[9]. Ferlay J, Bray F, Pisani P, Parkin DM. GLOBOCAN 2002: Cancer incidence, mortality and prevalence worldwide, version 2.0. IARC Cancer Base number 5. Lyon: IARC Press; 2004.

[10]. Sung JJ, Lau JY, Goh KL, Leung WK; Asia Pacific Working Group on Colorectal Cancer. Increasing incidence of colorectal cancer in Asia: implications for screening. Lancet Oncol. 2005;6:871-876.

[11]. Ntanasis-Stathopoulos J, Tzanninis JG, Philippou A, Koutsilieris M. Epigenetic regulation on gene expression induced by physical exercise. J Musculo skelet Neuronal Interact. 2013;13:133-146.

[12]. 18. Rawson JB, Sun Z, Dicks E, et al. Vitamin D intake is negatively associated with promoter methylation of the Wnt antagonist gene DKK1 in a large group of colorectal cancer patients. Nutr Cancer. 2012;64:919

[13]. World Cancer Research Fund and American Institute for Cancer Research Food, Nutrition, Physical Activity, and the Prevention of Cancer: A Global Perspective. Washington, DC: American Institute for Cancer Research; 2007.

[14]. Meyer JE, Narang T, Schnoll-Sussman FH, et al. Increasing incidence of rectal cancer in patients aged younger than 40 years: an analysis of the surveillance, epidemiology, and end results database. Cancer. 2010;116:4354-4359.

[15]. Keswani SG1, Boyle MJ, Maxwell JP 4th, Mains L, Wilks SM, Hunt JP, O'Leary JP.Colorectal cancer in patients younger than 40 years of age. 12412713

[16]. KK Chan,1,3 B Dassanayake,3 R Deen,2,3 RE Wickramarachchi,3 SK Kumarage,3 S Samita,4 and KI Deen.Analysis of survival and prognostic markers,young colorectal cancer.World J Surg Oncol. 2010; 8: 82. 2010 Sep 15. doi: 10.1186/1477-7819-8-82.

[17]. O'Connell JB, Maggard MA, Liu JH, Etzioni DA, Livingston EH, Ko CY. Do Young Colon Cancer Patients Have Worse Outcome? World Journal of Surgery. 2004;28:558-562. doi: 10.1007/s00268-004-7306-7.

[18]. Three-years report of Population Based Cancer Registries 2006-2008 (Detailed Tabulations of Individual Registries Data). National Cancer Registry Programme (Indian Council of Medical Research), Bangalore November 2010. Available from: http://www.PBCR 2006 2008.aspx, accessed on December 27, 2012.

[19]. O'Connell JB, Maggard MA, Liu JH, Etzioni DA, Livingston EH, Ko CY. Rates of Colon and Rectal Cancers are Increasing in The Young. The American Surgeon. 2003;69:866-872.

[20]. Alabaster O. Colorectal cancer: Epidemiology, risks and prevention. In: Ahlgren JD, Mc Donald JS, editors. Gastrointestinal Oncology. Philadelphia: JB Lipincott; 1972. p. 243-59.

[21]. Howlander N, Noone AM, Krapcho M, Neyman N, Aminou R, Waldron W et al. SEER cancer statistics review, $1975-2008$. Bethesda: National Cancer Institute; 2011

[22]. Aljebreen AM. Clinico-pathological patterns of colorectal cancer in Saudi Arabia: Younger with an advanced stage presentation. Saudi J Gastroenterol 2007;13:84-7

[23]. Wisedopas N, Thirabanjasak D, Chirakalwasan N, Taweevisit M. Histological variants of colorectal adenocarcinoma and clinicomorphological association. J Med Assoc Thai 2006;89:788-94.

[24]. Nath J, Wigley C, Keighley MR, Perakath B. Rectal cancer in young adults: A series of 102 patients at a tertiary care centre in India. Colorectal Dis 2009;11:475-9.

[25]. Pal M. Proportionate increase in incidence of colorectal cancer at an age below 40 years: An observation. J Cancer Res Ther 2006;2:97-9

[26]. Gupta S, Bhattacharya D, Acharya AN, Majumdar S, Ranjan P, Das S. Colorectal carcinoma in young adults: A retrospective study on Indian patients: 2000-2008. 
[27]. National Cancer Registry Programme. Population based cancer registries 2004-2005. New Delhi: Indian Council of Medical Research; 2008

[28]. Rasool S, Bari S, Rashid A, Wani R, Wani G. Peer: Outcome of patients with acute intestinal obstruction due to colorectal carcinoma. Int J Surg 2009;20: DOI: 10.5580/C35

[29]. Cohen AM, Minsky BD, Schilsky RL. In: De Vita TV, Hellman S, Rosenberg SA, et al. editors. Cancer: Principles and Practice of Oncology. $4^{\text {th }}$ ed. Philadelphia: J.B. Lippincott Company; 1993. p. 931

[30]. Cancer, Principles and Practice of Oncology. Edited by de Vita VT Jr, et al . 4th ed. JB Lippincott Co: Philadelphia; p. 941.

[31]. Antelo M, Balaguer F, Shia J, Shen Y, Hur K, Moreira L, Cuatrecasas M, Bujanda L, Giraldez MD, Takahashi M, et al. A high degree of LINE-1 hypomethylation is a unique feature of early-onset colorectal cancer. PLoS One. 2012;7:e45357.

[32]. Walters RJ, Williamson EJ, English DR, Young JP, Rosty C, Clendenning M, Walsh MD, Parry S, Ahnen DJ, Baron JA, et al. Association between hypermethylation of DNA repetitive elements in white blood cell DNA and early-onset colorectal cancer. Epigenetics. 2013;8:748-755 